\title{
Article \\ A Design Method to Assess the Primary Strength of the Delta-Type VLFS
}

\author{
Roy Gafter*(D) and Nitai Drimer \\ Faculty of Mechanical Engineering, Technion-Israel Institute of Technology, Haifa 3200003, Israel; \\ nitaid@technion.ac.il \\ * Correspondence: gafter@campus.technion.ac.il; Tel.: +972-54-5227211
}

check for

updates

Citation: Gafter, R.; Drimer, N. A Design Method to Assess the Primary Strength of the Delta-Type VLFS. J. Mar. Sci. Eng. 2021, 9, 1026. https:// doi.org/10.3390/jmse9091026

Academic Editor: Weicheng Cui

Received: 27 August 2021

Accepted: 16 September 2021

Published: 18 September 2021

Publisher's Note: MDPI stays neutral with regard to jurisdictional claims in published maps and institutional affiliations.

Copyright: (c) 2021 by the authors. Licensee MDPI, Basel, Switzerland. This article is an open access article distributed under the terms and conditions of the Creative Commons Attribution (CC BY) license (https:// creativecommons.org/licenses/by/ $4.0 /)$.

\begin{abstract}
Very large floating structure (VLFS) is a sustainable concept centered around creating solid platforms at sea. The Delta is a new type of VLFS, designed to withstand open-sea conditions and to form, in addition to a broad deck areas, a sheltered basin of year-round operability. The design of this unique hull relies on direct calculations in order to identify critical load cases and assess their load effects. This study formulates a theoretical procedure for the initial assessment of the primary strength. The procedure analytically integrates the floatation loads while the hull rests at hydrostatic equilibrium on a wave surface and obtains the vertical and horizontal bending moment. This preliminary assessment tool enables a fast review of many load cases and provides the basic insights necessary for a reasonable initial design. Using the procedure, we conducted a primary load assessment for the design of Delta. By calculating the load response to 588 load cases, we identified the critical load scenario and the maximal axial stress. As the stress was too high, we improved the geometry in order to reduce loads and assessed proper scantlings for the critical section. We present the formulation of the procedure, the validation of the results, and the implementation for the structural design of the Delta VLFS.
\end{abstract}

Keywords: VLFS; hull girder; primary strength; structural analysis

\section{Introduction}

The creation of artificial land at sea for industrial, commercial, or recreational infrastructures may resolve many of the problems generated by high population density along the coast [1-3]. Based on floatation, with minimal impact on marine habitats and natural current flow, very large floating structure (VLFS) is a sustainable technology that can be utilized for moving land-based operations out to sea [4-7].

Currently, VLFSs are classified into two broad categories: the pontoon-type, limited to relatively sheltered water, and the semi-submersible type, for the open ocean $[8,9]$. The authors of [10] presents a new concept, the Delta-type VLFS, for intermediate opensea conditions. An essential feature of the Delta-type is the formation of a sheltered basin, providing accessibility for ships in most sea states. The authors of [10] presents the Delta VLFS concept and studies its hydrodynamic aspects. The hydrodynamic parametric analysis, which is at the heart of that study, examined the motion response of the structure and wave reduction levels at the protected basin. We found that the response to wave periods of up to $20 \mathrm{~s}$ is favorable. The structure maintains very low motion response and the wave heights at the basin are significantly reduced. A preliminary design and analysis of the mooring system is presented in that paper as well. In order to advance the practical development of the concept, this paper focuses on the structural aspects of the Delta VLFS concept and presents a design method for the preliminary assessment of the hull's primary strength. Figure 1 presents an application example of the Delta VLFS as a desalination plant utilizing wind energy. The hull is sufficiently stable for carrying three turbines of $5 \mathrm{MW}$ each arranged to minimize wind interference. It provides space for the desalination plant and a sheltered port for sea transportation. 


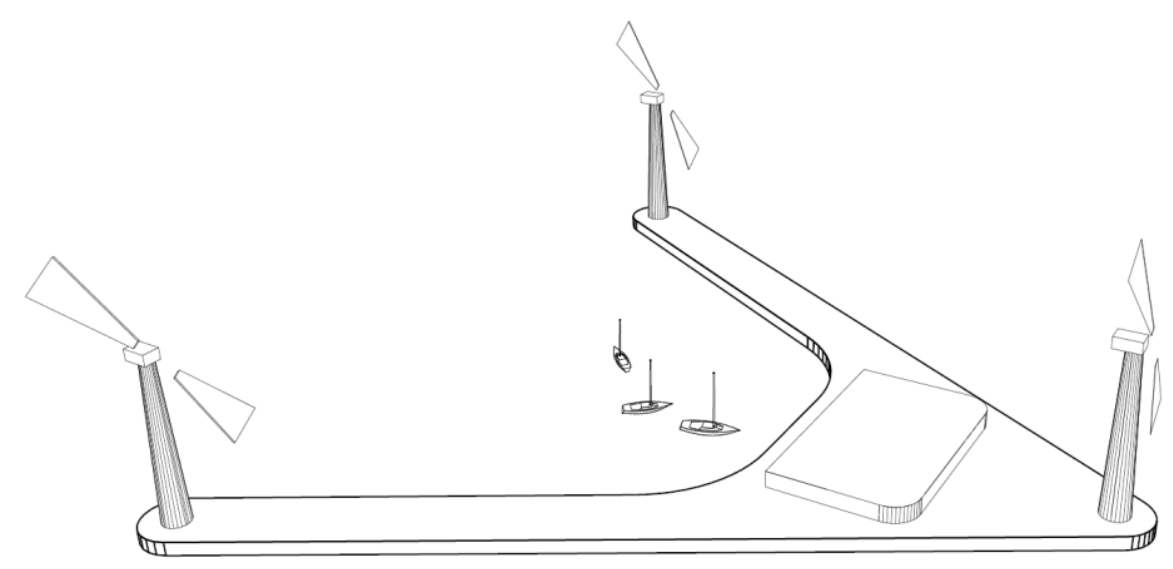

Figure 1. Application example of the Delta very large floating structure (VLFS).

Over the years, vast accumulated experience and knowledge of the design, construction, and operation of ships have resulted in the formulation of rules and standards for the design and construction of ships and offshore structures. As detailed by [11,12], these rules provide an empirical design formulation for the design of vessels and result in the specification of scantlings. In many practical cases, the formulation relies on hydrostatic loading, while accounting for the actual hydrodynamic occurrence using specified dynamic factors.

For marine structures of a non-conventional shape, such accumulative experience does not exist and the design must rely on direct analysis from the early stages [13-15]. In cases where it is reasonable to assume that a structure is sufficiently rigid such that hydroelastic effects are negligible, an acceptable analysis procedure is composed of a hydrodynamic model. Followed by a structural model, the hydrodynamic analysis provides pressure distribution and body loads (as rigid body accelerations), as presented by [16] and [17]. However, this comprehensive analysis requires the specification of the geometry and materials for all the structural components and the setting of a complex global model. In order to minimize the iterative process of running and modifying the complex global model, it is essential to conduct a good initial assessment of the primary strength and a reasonable preliminary design of the scantlings.

In the early design stages of a conventional ship hull, it is acceptable and supported by design rules to assume that the critical primary load is the longitudinal bending moment while floating at quasi-static equilibrium on a wave along the ship. The wavelength is equal to the waterline length, and the phase is such that either the wave crest (hogging) or the wave trough (sagging) is at midship [18-21]. To assess the primary strength of the Delta's hull, we assume hydrostatic rest on a wave surface as well; however, it is not trivial to assume the critical wave parameters (i.e., length, direction, and phase).

Here, we present an analytical hydrostatic procedure for the preliminary assessment of these critical wave parameters and the required cross section strength properties. Our procedure integrates the incremental floatation loads while the hull rests at hydrostatic equilibrium on a wave of specified parameters in order to obtain the vertical and horizontal bending moment. This preliminary assessment tool enables a fast review of many load cases and provides the basic insights necessary for a reasonable initial design. Thus, the procedure is valuable as a step preceding the time-consuming and comprehensive hydrodynamic-structural analysis.

The rest of this paper is structured as follows. Section 2 presents the methodology and formulation, while Section 3 provides verification and validation of the procedure. In addition, Section 3 outlines the application of the procedure for the preliminary global structural design of the Delta VLFS. Finally, Section 4 contains discussion, and Section 5 contains the conclusions. 


\section{Materials and Methods}

Hull strength is among the most basic design considerations in the structural design of marine structures. As reviewed by [22,23], in terms of the hull's structural response, the design criterion has gradually changed to yielding, buckling, and ultimate limit states (ULSs). The authors of $[24,25]$ defined ULS as the total failure ("collapse") of the structure as a result of a reduction in structural stiffness and strength. That loss of stiffness is related to yielding, plastic collapse, or buckling of a structural member, section, or the entire structure. ULS assessment is a basic and essential part of the structural design of ships and offshore structures and is considered a mandatory practice by the maritime industry [26-28].

Methods for the evaluation of ultimate hull girder strength may be classified as simplified or advanced methods. The advanced methods, such as the idealized structural unit method (ISUM) or the nonlinear finite element (FE) method, are based on a direct approach and allow for the analysis of more realistic failure mechanisms and loading scenarios, as presented by [21,29] and others. In the simplified methods, the hull girder's ultimate strength is approximated from yielding and elastic considerations, which, in many cases, rely on analytical calculations and empirical data. Box girder analysis, where the hull is simplified into a thin-walled box beam in extreme hogging or sagging states, is one of the simplified analysis methods. Geometric simplification, wave loading assumptions, and application of beam theory that are used in this analysis method date back almost two hundred years. In the early stages of design, such procedures are still widely use today $[29,30]$.

The presented analytical-hydrostatic procedure is a simplified analysis method formulated to provide an initial estimation of the hull's strength requirements for the structural design of the Delta VLFS. Consisting of beam theory and analytical calculations of the applied bending moments, the procedure is equivalent to the described box girder analysis method. However, since the Delta is not a ship-like structure, the extreme load cases are not trivial. Therefore, we consider a range of wave load cases and analytically calculate the applied bending moments for each wave direction, length, and phase.

The first stage of the preliminary procedure is to determine the hydrostatic equilibrium position of the structure under incoming monochromatic wave conditions using the GHS software. The GHS model represents the structure's geometry by transverse cross sections and a weight distribution which balances the floating state on calm water at zero list and trim angles. GHS solves the equilibrium position on a wave in terms of vertical position, heel, and trim, which are inputs for the analytical calculation of the applied loads.

The identification of the critical cross section is not as trivial as in traditional ship design. While for typical ships subjected to hogging or sagging states, the critical cross section is at midship; it is expected that the critical cross section of the Delta VLFS is near the connection between the fore triangular hull and the side-hulls (see Figure 2). In terms of primary strength, it is subjected to high bending moments at head seas of critical wavelength and probably more at head-beam seas with a critical combination of wavelength and direction, where one side-hull will be lifted and the other will be lowered.

The analytical load calculations are based on the integration of the hydrostatic pressure applied to the wetted surface of the hull and the hull's weight while resting in hydrostatic equilibrium on the free surface of an assumed incoming wave.

By adopting practical ship design assumptions, we assume a long crested, sinusoidal (monochromatic) wave. The water surface equation, in terms of the main coordinate system, is formulated as the following:

$$
\eta=a \cdot \cos [k(x \cos \beta+y \sin \beta)+\varphi],
$$

where $\eta$ is the water elevation, $a$ is the wave amplitude, $k$ is the wave number, $\beta$ is the wave direction angle, $\varphi$ is the wave phase, and $x$ and $y$ are the spatial coordinates of the main coordinate system (presented in Figure 2). Positive wave direction angle is defined in a contraclockwise manner, from the positive $\mathrm{x}$ axis (for head sea $s \beta=0$ ). 


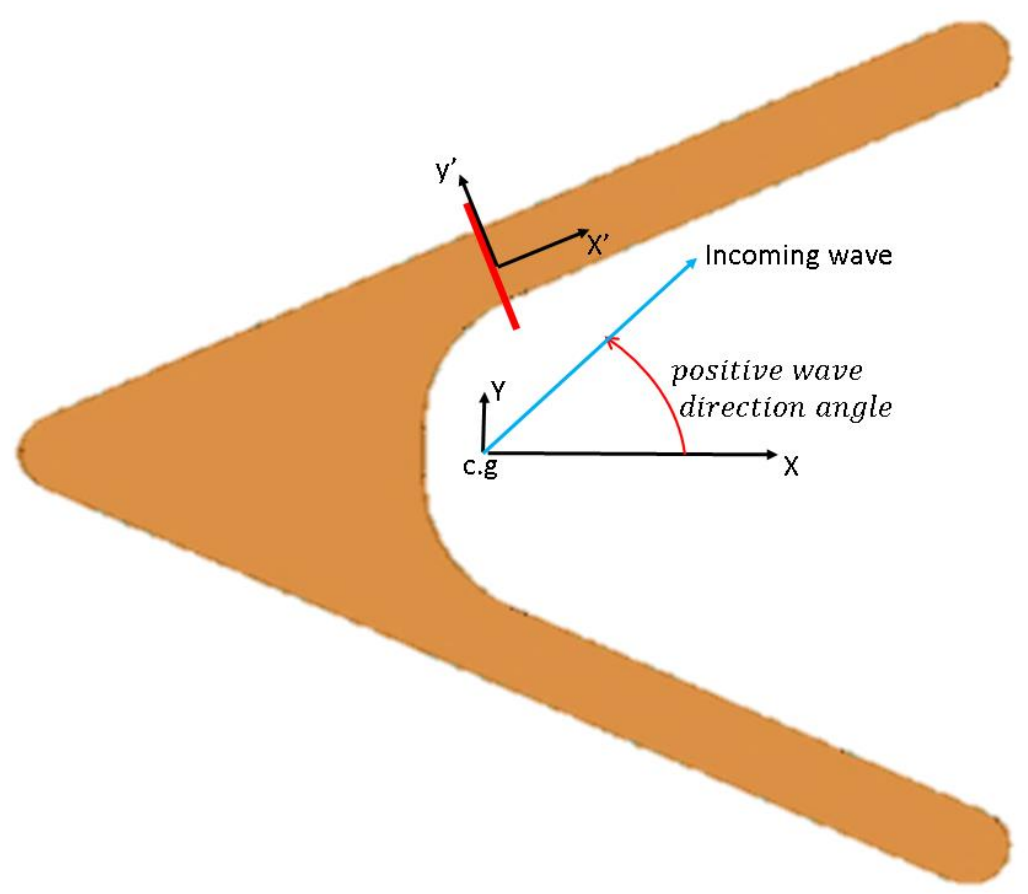

Figure 2. The Delta VLFS initial configuration (top view). The assumed critical cross section, marked with a red line, is at the connection of the side-hull to the front delta. The origin of the global coordinate system $(\boldsymbol{x}, \boldsymbol{y})$ is at the center of gravity of the structure, and the vertical axis is positive upwards from the calm free surface.

The hydrostatic pressure under quasi-static wave surface $P(x, y, z)$ is defined as follows:

$$
P(x, y, z)=\rho_{w} g \cdot\{a \cdot \cos [k(x \cos \beta+y \sin \beta)+\varphi]-z\},
$$

where $\rho_{w}$ is the water density, $g$ is the acceleration of gravity, and $z$ is the vertical spatial coordinate.

In terms of the local (tagged) coordinate system, defined along the centerline of a side-hull, the hydrostatic water pressure function takes the following form:

$$
P\left(x^{\prime}, y^{\prime}, z^{\prime}\right)=\rho_{w} g a \cdot \cos \left(H_{x} \cdot x^{\prime}+H_{y} \cdot y^{\prime}+H_{z} \cdot z^{\prime}+H_{c}\right)-\rho_{w} g\left(W_{c}+W_{x} x^{\prime}+W_{y} y^{\prime}+W_{z} z^{\prime}\right),
$$

where $H_{x}, H_{y}, H_{z}$, and $H_{c}$ are defined as follows:

$$
\begin{gathered}
H_{x} \equiv k \cdot\left[\alpha_{11} \cos (\beta) \cos \left(\alpha_{1}\right)+\alpha_{21} \cos (\beta) \sin \left(\alpha_{1}\right)+\alpha_{12} \sin (\beta) \cos \left(\alpha_{1}\right)+\alpha_{22} \sin (\beta) \sin \left(\alpha_{1}\right)\right] \\
H_{y} \equiv k \cdot\left[-\alpha_{11} \cos (\beta) \sin \left(\alpha_{1}\right)+\alpha_{21} \cos (\beta) \cos \left(\alpha_{1}\right)-\alpha_{12} \sin (\beta) \sin \left(\alpha_{1}\right)+\alpha_{22} \sin (\beta) \cos \left(\alpha_{1}\right)\right], \\
H_{z} \equiv k \cdot\left[\alpha_{31} \cos (\beta)+\alpha_{32} \sin (\beta)\right],
\end{gathered}
$$

and

$$
H_{c} \equiv k \cdot\left[\alpha_{11} R_{x} \cos (\beta)+\alpha_{21} R_{y} \cos (\beta)+\alpha_{12} R_{x} \sin (\beta)+\alpha_{22} R_{y} \sin (\beta)\right]+\varphi,
$$

where $\alpha_{1}$ is the angle between the positive axes $x$ and $x^{\prime}$, and $R_{x}, R_{y}$, and $R_{z}$ are the $x, y, z$ components of the vector $R$ which extends from the origin of the global coordinate system to the origin of the local (tagged) system (see Figure 3). 


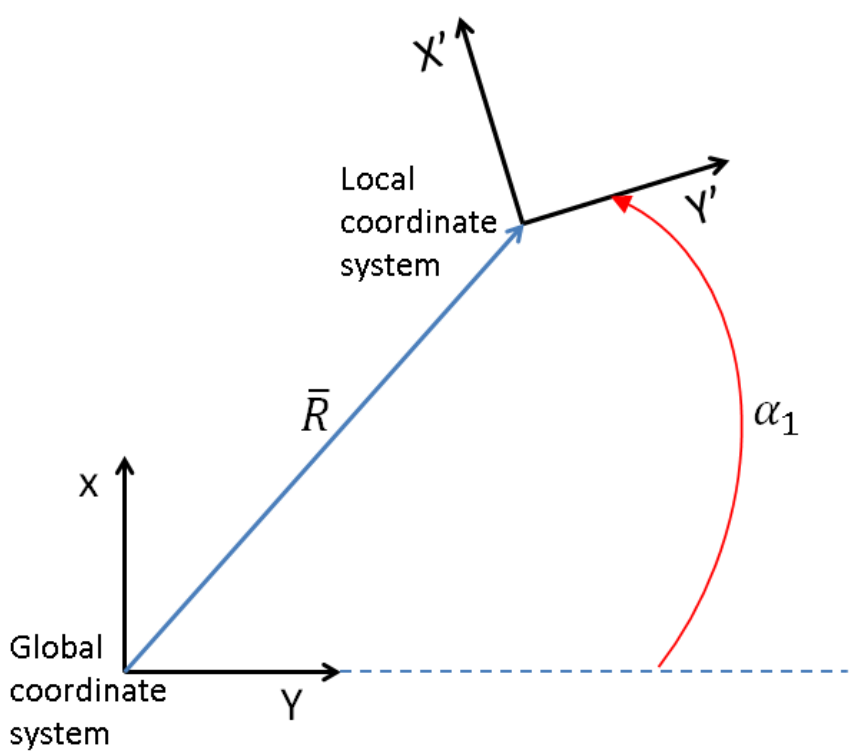

Figure 3. Global and local coordinate systems. In this analysis, the origin of the global coordinate system is at C.G. and the origin of the local system is at the connection point of the side-hull, as presented in Figure 2.

The terms $\alpha_{i j}$ are orientation cosines for the transformation from the global to the local coordinate system. As shown in Figure 2, the origin of the local coordinate system is located at the connection point of the side-hull. The positive $x^{\prime}$ axis points to the stern along the centerline of the side-hull, and the $z^{\prime}$ axis points upwards from the calm water line.

The orientation cosines are defined as follows:

$$
\begin{gathered}
\alpha_{11} \equiv \cos \phi \\
\alpha_{21} \equiv 0 \\
\alpha_{31} \equiv \sin \phi \\
\alpha_{12} \equiv \sin \theta \cdot \sin \phi \\
\alpha_{22} \equiv \cos \theta \\
\alpha_{32} \equiv-\sin \theta \cdot \cos \phi \\
\alpha_{13} \equiv-\cos \theta \cdot \sin \phi \\
\alpha_{23} \equiv \sin \phi
\end{gathered}
$$

and the following is the case:

$$
\alpha_{33} \equiv \cos \theta \cdot \cos \phi,
$$

where $\phi$ and $\theta$ are the trim and heel angles, respectively.

The terms $W_{x}, W_{y}, W_{z}$, and $W_{c}$ of Equation (3) are defined as the following:

$$
\begin{gathered}
W_{x} \equiv \alpha_{13} \cos (\theta)+\alpha_{23} \sin (\theta), \\
W_{y} \equiv-\alpha_{13} \sin (\theta)+\alpha_{23} \cos (\theta), \\
W_{z} \equiv \alpha_{33},
\end{gathered}
$$

and the following is the case:

$$
W_{c} \equiv \alpha_{13} R_{x}+\alpha_{23} R_{y}+V_{e r}
$$

where $V_{e r}$ is the vertical position (in the $z$ direction) of the structure, defined as the change in the vertical position of the center of gravity from the calm water position, measured from the undisturbed water line. 
By integrating the pressure along the wetted surface using Equation (3), we obtain the distributed hydrostatic forces (per unit length) along the side-hull.

The hydrostatic force applied to the bottom of the hull is the following:

$$
F_{h b}\left(x^{\prime}\right)=\int_{y_{d}\left(x^{\prime}\right)}^{y_{u}\left(x^{\prime}\right)} P\left(x^{\prime}, y^{\prime}, z^{\prime}=D_{r}\right) d y^{\prime}
$$

and the hydrostatic forces applied to the sides are

$$
F_{h s d}\left(x^{\prime}\right)=\int_{d r a f t}^{z_{w l}\left(x^{\prime}, y^{\prime}\left(x^{\prime}\right)\right)} P\left(x^{\prime}, y^{\prime}(x), z^{\prime}\right) d z^{\prime}
$$

and

$$
F_{h s u}\left(x^{\prime}\right)=-\int_{\text {draft }}^{z_{w l l}\left(x^{\prime}, y^{\prime}\left(x^{\prime}\right)\right)} P\left(x^{\prime}, y^{\prime}(x), z^{\prime}\right) d z^{\prime},
$$

where $D_{r}$ is the draft, and $y_{u}\left(x^{\prime}\right)$ and $y_{d}\left(x^{\prime}\right)$ are the equations of the upper $\left(y^{\prime}>0\right)$ and lower $\left(y^{\prime}<0\right)$ edges of the bottom, respectively. In a similar manner, $F_{h s u}$ and $F_{h s d}$ are the hydrostatic forces applied on the positive and negative (in terms of the local coordinate system) sides of the hull. $z_{w l}$ is the water level at any point along the sides of the hull.

Assuming even distribution, at this preliminary stage, the weight of the hull per unit length is the following:

$$
F_{w z}\left(x^{\prime}\right)=-\alpha_{33} g \rho_{w} \cdot\left(y_{u}\left(x^{\prime}\right)-y_{d}\left(x^{\prime}\right)\right) \cdot D_{r}
$$

in the vertical $\left(z^{\prime}\right)$ direction and

$$
F_{w y}\left(x^{\prime}\right)=-\alpha_{13} g \rho_{w} \cdot\left(y_{u}\left(x^{\prime}\right)-y_{d}\left(x^{\prime}\right)\right) \cdot D_{r} .
$$

in the horizontal $\left(y^{\prime}\right)$ direction.

The total distributed load (force) per unit of length is obtained by summing Equations (12) and (15) for the vertical ( $\left.z^{\prime}\right)$ direction and summing Equations (13), (14), and (16) for the horizontal $\left(y^{\prime}\right)$ direction.

Following beam theory, integration of the distributed force along the hull results in shear force distribution and integration of the shear force results in the bending moment. We obtain the following:

$$
V_{z}\left(x^{\prime}\right)=\int\left[F_{h b}\left(x^{\prime}\right)+F_{w z}\left(x^{\prime}\right)\right] d x^{\prime}
$$

and

$$
M_{y}\left(x^{\prime}\right)=\int\left[V_{z}\left(x^{\prime}\right)+c_{1}\right] d x^{\prime}
$$

in the vertical plane and

$$
V_{y}\left(x^{\prime}\right)=\int\left[F_{h s d}\left(x^{\prime}\right)+F_{h s u}\left(x^{\prime}\right)+F_{w z}\left(x^{\prime}\right)\right] d x^{\prime}
$$

and

$$
M_{z}\left(x^{\prime}\right)=\int\left[V_{y}\left(x^{\prime}\right)+c^{\prime}{ }_{1}\right] d x^{\prime}
$$

in the horizontal plane.

The constants of integration are determined by considering the free stern of the sidehull, where the shear forces and bending moments are zero. 


\section{Results}

\subsection{Verification}

\subsubsection{Comparison with Geometrical CAD Calculations}

We verified the analytical solution by comparing the bending moment at the assumed critical cross section with geometrical calculations using SOLIDWORKS. As presented in Figure 4, with the hull positioned at hydrostatic equilibrium (i.e., heel, trim, and depth) on a specified wave surface as solved by GHS, we split the solid model of the hull by the wave surface. SOLIDWORKS solves the submerged volume and center of volume of the side-hull. The net shear force and vertical bending moment applied by the side-hulls at the critical cross section are calculated by subtracting the weight from the buoyancy force.

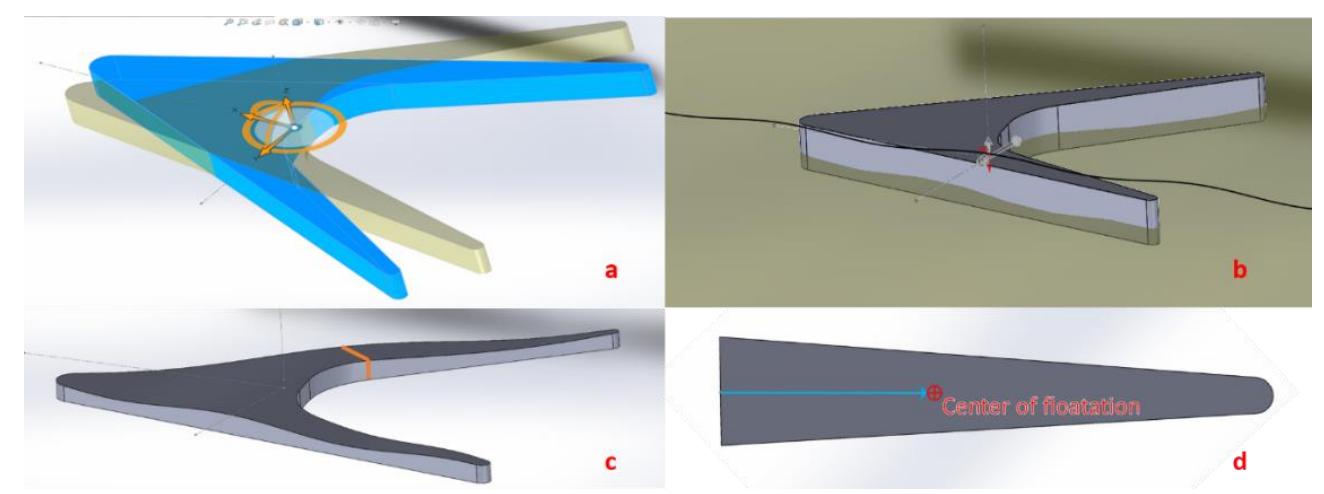

Figure 4. A demonstration of load calculation by CAD: (a) positioning the structure at the equilibrium position as calculated by GHS (draft, list, and trim); (b) setting the incoming wave surface; (c) trimming the solid hull by the wave surface, keeping the underwater part; (d) cutting the side-hull at the critical cross section (marked in orange in (c)) and finding the center of floatation, the moment arm (blue arrow in (d)), and the volume for the load calculations.

The calculated net loads in various hydrostatic equilibrium positions were close to the loads in similar conditions that were calculated by the analytical procedure. Figure 5 presents a comparison of the results assuming a $450 \mathrm{~m}$ long and $10 \mathrm{~m}$ high wave in incoming directions of $45^{\circ}, 30^{\circ}$, and $15^{\circ}$.
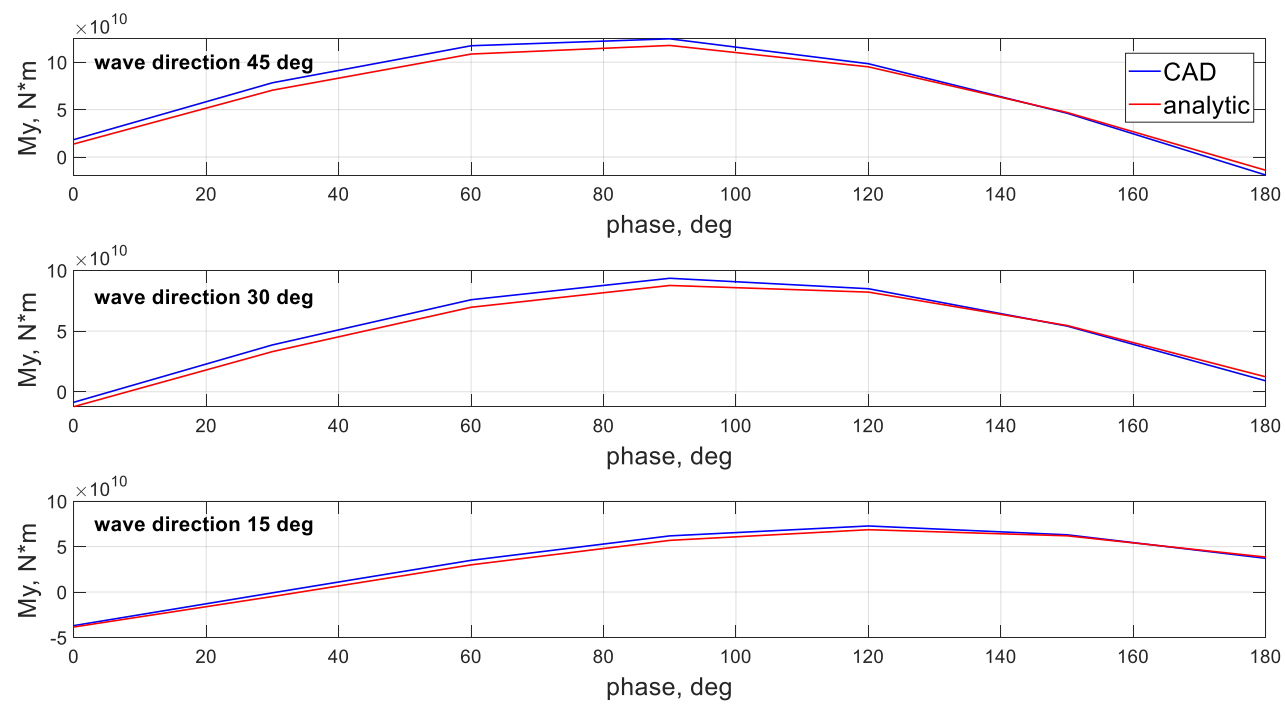

Figure 5. A comparison of bending moments between the CAD and analytical models, for three wave directions: $45^{\circ}$ (top), $30^{\circ}$ (middle), $15^{\circ}$ (bottom). 
3.1.2. Comparing the Quasi-Static Primary Strength Loads with Hydrodynamic Splitting Forces

By post-processing the hydrodynamic diffraction and radiation analysis, AQWA AGS calculates splitting forces and moments applied to a specified portion of a structure. The moments are determined about a selected reference point in the directions of the main coordinate system of the hydrodynamic analysis.

As detailed by the AQWA theory manual [31], the different forces and moments are as follows:

\section{A. External hydrodynamic}

$$
\bar{F}_{f}(\omega)=\iint_{S_{B}}(-p \bar{n}) d S \bar{M}_{f}(\omega)=\iint_{S_{B}}\left[\left(\bar{X}-\bar{X}_{Q}\right) \times(-p \bar{n})\right] d S,
$$

where $\omega$ is the wave frequency, $\bar{X}_{Q}$ is the reference point location vector, $S_{B}$ is the wetted surface of the part of interest, and $\bar{n}$ is the normal vector of the wetted surface pointing outward from the part of the structure. $p$ is the summation of hydrostatic and hydrodynamic pressure. Consisting of the incident, diffraction, and radiation waves, the hydrodynamic pressure and the resulting loads are calculated and can be specified separately.

\section{B. Gravitational:}

$$
\bar{F}_{g}(\omega)=\sum\left\{\left(0,0,-m_{j} g\right)-\bar{\theta} \times\left(0,0,-m_{j} g\right)\right\}, \bar{M}_{g}(\omega)=\sum\left\{\left(\bar{X}_{j}-\bar{X}_{Q}\right) \times\left[\left(0,0,-m_{j} g\right)-\bar{\theta} \times\left(0,0,-m_{j} g\right)\right]\right\},
$$

Here, $\bar{\theta}$ is the rotational motion response, $m_{j}$ is the mass at location $\bar{X}_{j}$, and $g$ is the gravitational acceleration.

\section{Inertial:}

$$
\bar{F}_{m}(\omega)=\omega^{2} \sum m_{j}\left(u_{j}, v_{j}, w_{j}\right) \bar{M}_{m}(\omega)=\sum\left\{m_{j}\left(\bar{X}_{j}-\bar{X}_{Q}\right) \times\left(u_{j}, v_{j}, w_{j}\right)\right\},
$$

Here, $\left(u_{j}, v_{j}, w_{j}\right)$ is the motion response vector at location $\bar{X}_{j}$.

The calculated loads may be stipulated separately or summed up into partial or total load. The incident load part can be used for the verification process.

As detailed by [32], considering the 2D incident wave potential $\left(\Phi_{I}\right)$ of the following form:

$$
\Phi_{I}=\frac{\eta g}{\omega} \cdot \frac{\cosh k(h+z)}{\cosh (k h)} \cdot \sin (k x-\omega t)
$$

in shallow water, the pressure $(p)$ may be approximated as follows:

$$
p=-\rho g z-\rho \frac{\partial \Phi_{I}}{\partial t}=-\rho g z+\rho g \eta \cos (k x-\omega t),
$$

where $\eta$ is the wave amplitude, $k$ is the wave number, $h$ is the water depth, $\rho$ is the water density, $x$ and $z$ are horizontal and vertical coordinates, and $t$ is time. Therefore, the pressure is mainly hydrostatic.

If a free-floating structure is positioned at hydrostatic equilibrium in calm water, the weight of the structure is counterbalanced by the contribution of the $\rho g z$ term in Equation (9). In this case, the applied loads are the result of the incident wave alone, contributed by the second term $\left(\rho \frac{\partial \Phi_{I}}{\partial t}\right)$ of Equation (22). If the mass is evenly distributed along the structure, it will remain true for part of the structure as well.

For this verification, we conducted complete hydrodynamic analysis using AQWA. The structure was fixed in its calm water hydrostatic equilibrium position, and the incoming wave splitting forces were calculated at the critical cross section. As expected, the calculated loads were close to the ones obtained by the analytic calculations for similar conditions. Figures 6 and 7 present examples comparing these results. 

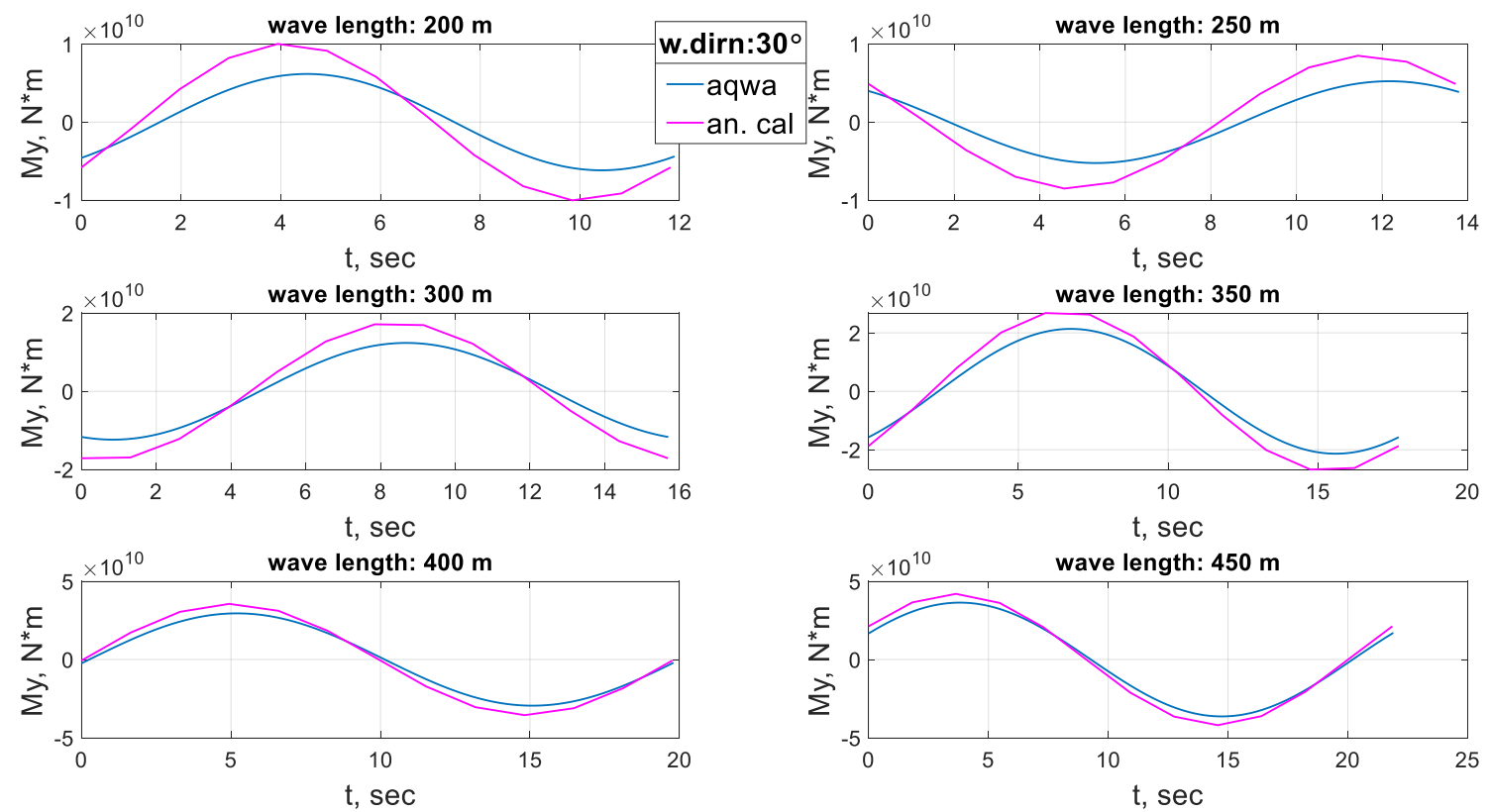

Figure 6. A comparison of vertical bending moments $\left(M_{y}\right)$. The incident wave splitting forces calculation by AQWA is in blue, while the hydrostatic wave load by analytic calculation is in magenta. From top to bottom, left to right: bending moment plots for wavelengths of $200 \mathrm{~m}, 250 \mathrm{~m}, 300 \mathrm{~m}, 350 \mathrm{~m}, 400 \mathrm{~m}, 450 \mathrm{~m}$.
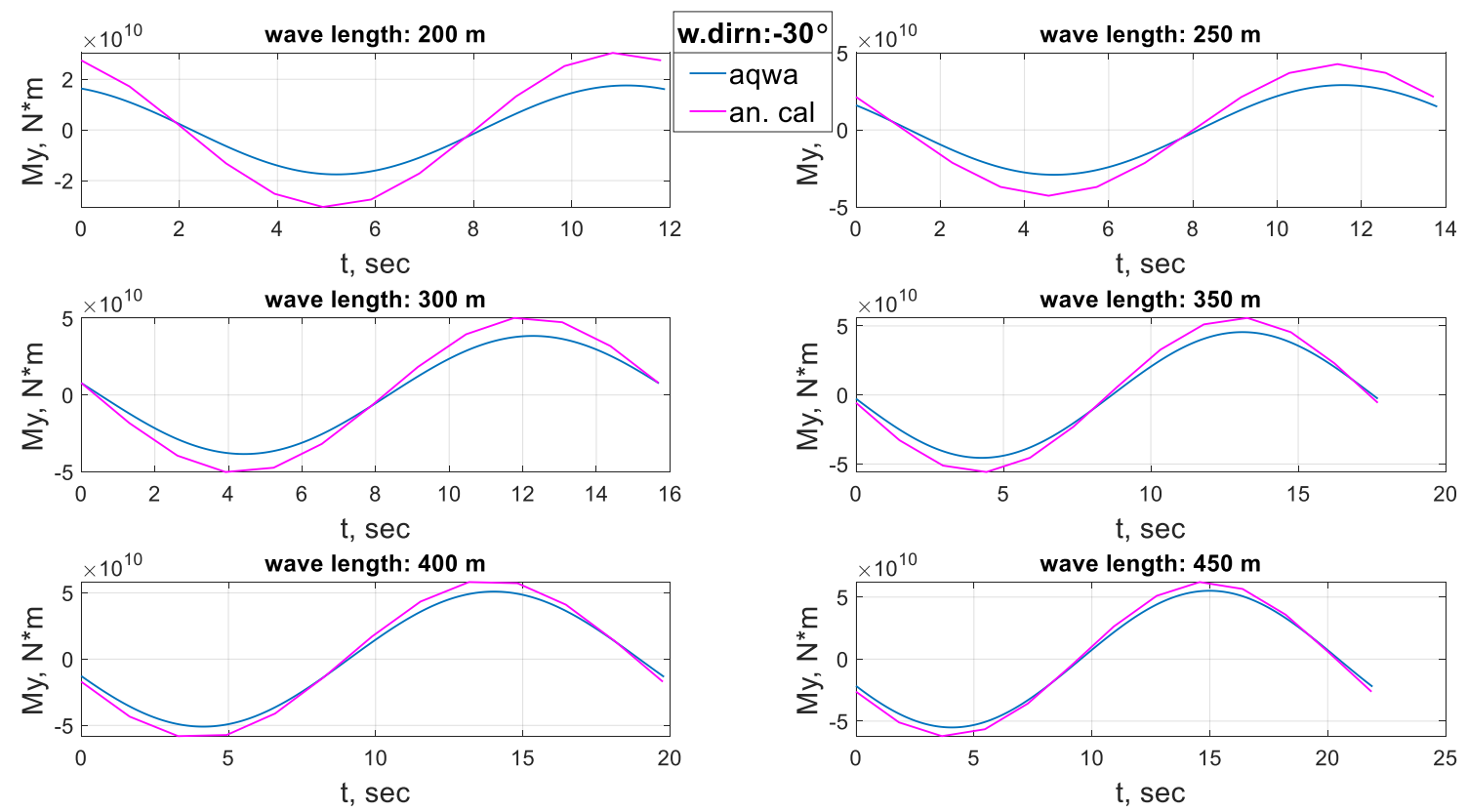

Figure 7. A comparison of vertical bending moments $\left(M_{y}\right)$. The incident wave splitting forces calculation by AQWA is in blue, while the hydrostatic wave load by analytic calculation is in magenta. From top to bottom, left to right: bending moment plots for wavelengths of $200 \mathrm{~m}, 250 \mathrm{~m}, 300 \mathrm{~m}, 350 \mathrm{~m}, 400 \mathrm{~m}, 450 \mathrm{~m}$.

\subsection{Total Hydrodynamic Load Comparison: Validation of the Procedure}

We do not expect that the loads calculated using the analytic hydrostatic procedure will accurately follow the actual hydrodynamic loads. However, as an initial design tool, the procedure should reflect the general trends and provide an adequate estimation in terms of the critical wave scenarios and the corresponding loads.

For the validation of the analytic procedure, we compared the total sum of the hydrodynamic splitting forces calculated by AQWA to the results of the simplified analytic procedure at identical wave conditions. Figure 8 presents the maximal (over a wavelength) 
vertical $\left(M_{y}\right)$ and horizontal $\left(M_{z}\right)$ bending moments obtained by AQWA and the analytic procedure.

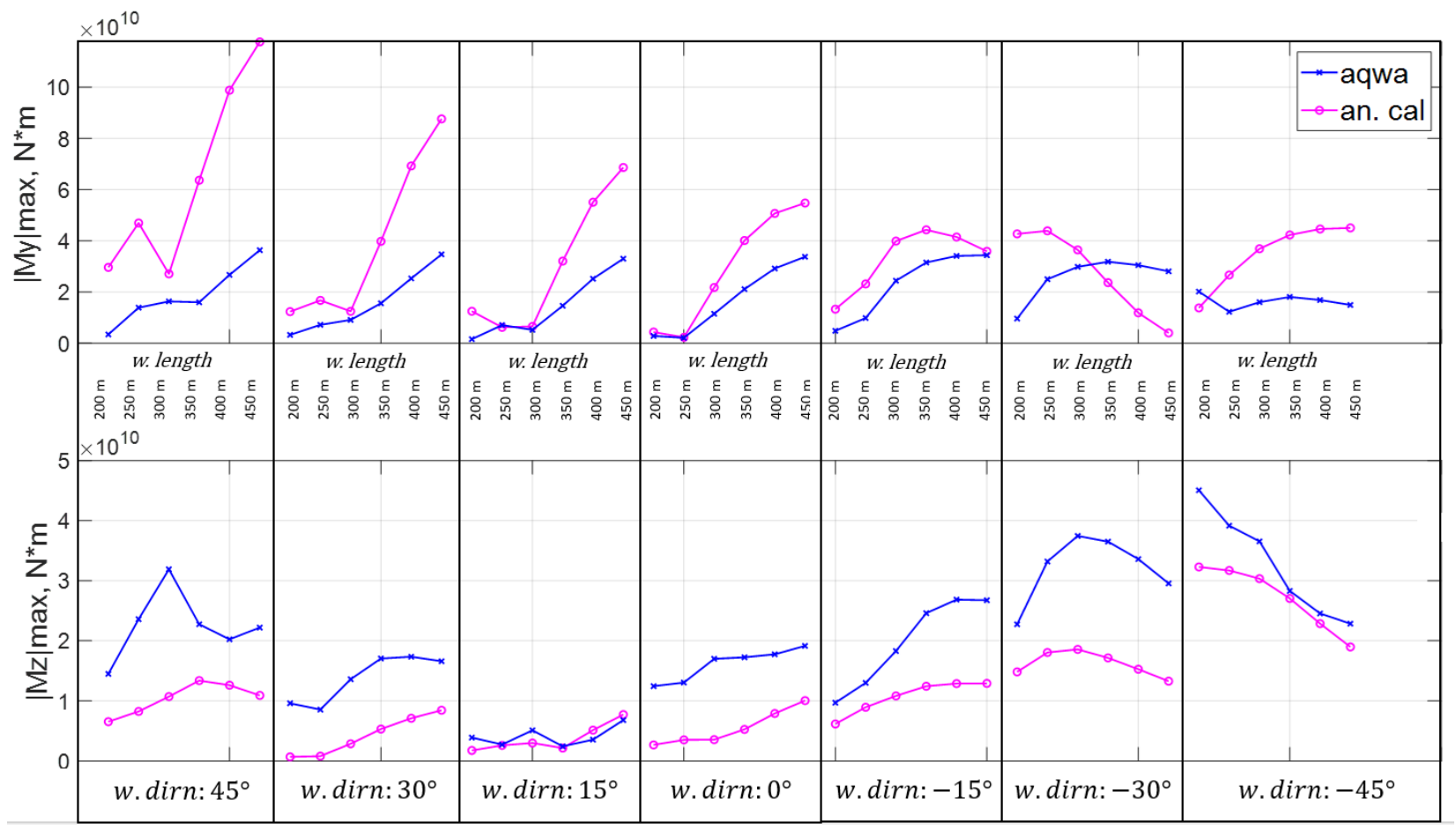

Figure 8. A comparison of the maximal bending moments $M_{y}$ (upper sub figure) and $M_{z}$ (lower sub figure). The wave splitting forces calculation by AQWA (complete hydrodynamic solution) is in blue. The hydrostatic wave load by analytic calculation is in magenta. Each subplot presents a wave direction. For each direction, the wavelength increased from 200 to $450 \mathrm{~m}$.

An examination of the maximal hydrodynamic load values (in blue in Figure 8) reveals that the bending moments in the vertical plane $\left(M_{y}\right)$ generally increase with the length of the incoming waves. The largest value is reached for wave of $450 \mathrm{~m}$ from the direction $45^{\circ}$. For the bending moments in the horizontal plane $\left(M_{z}\right)$, the maximal load is obtained by a $200 \mathrm{~m}$ long wave from an incoming direction of $-45^{\circ}$. The simplified analytical hydrostatic model results result in similar conclusions (in magenta in Figure 8). The bending moments in the vertical plane are generally higher than the bending moments in the horizontal plane, cause the most critical load effects, and are generally higher than in the hydrodynamic calculations.

\subsection{Implementation of the Design Procedure: Initial Results for Prismatic Side-Hulls}

In the initial geometry of the Delta VLFS, we designed side-hulls of even breadth (see Figure 9). We first implemented the analytical procedure for the evaluation of this design. By searching for critical wave conditions and maximal loads, we examined 588 wave scenarios combining the following range of parameters:

- Wave height: $10 \mathrm{~m}$;

- Wavelength: 100, 150, 200, 250, 300, 350, $400 \mathrm{~m}$;

- Wave phase: $0^{\circ}$ to $330^{\circ}$, in $30^{\circ}$ intervals. Phase $0^{\circ}$ is where the wave crest is at LCG;

- Wave direction: $45^{\circ}, 30^{\circ}, 15^{\circ}, 0^{\circ},-15^{\circ},-30^{\circ},-45^{\circ}$;

- The required bending moduli of the critical cross section are in the order of $1000 \mathrm{~m}^{3}$. 


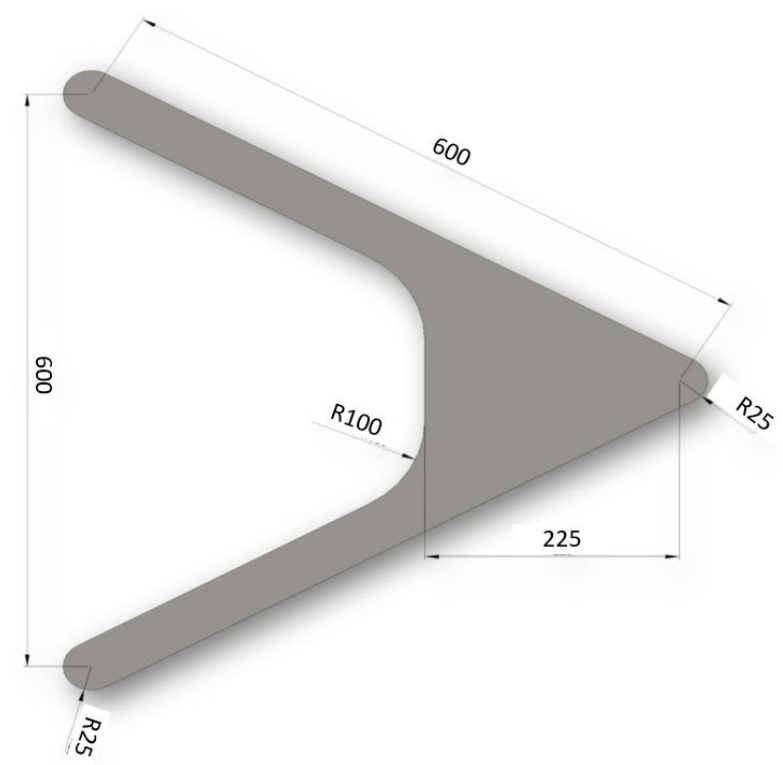

Figure 9. Initial prismatic design of the Delta VLFS.

The product of running the procedure over the 588 wave combinations is a MATLAB interactive plot, as illustrated in Figure 10. Such representation provides an immediate identification of the potentially critical wave scenario from the vast number of cases. On the final step, the specific critical wave and its corresponding stress level are obtained by simply placing the cursor over a suspected stress peak on the plot.

The analysis results in the following critical wave parameters: wavelength $200 \mathrm{~m}$, wave direction $-45^{\circ}$, and wave phase $300^{\circ}$. The vertical and transverse bending moments using these critical wave parameters are $M y=1.85 \cdot 10^{11} \mathrm{Nm}$ and $M z=4.7 \cdot 10^{10} \mathrm{Nm}$, respectively. The maximum axial stress for a critical cross section of a bending modulus $z_{y} \cong z_{z} \cong 1000 \mathrm{~m}^{3}$ is about $230 \mathrm{MPa}$.

We consider an axial stress of $230 \mathrm{MPa}$ (near the yield strength of mild structural steel) as too high. To account for dynamic effects, higher waves, and prudent safety factors for a new concept, the allowable stress should be significantly lower. Furthermore, the required bending moduli imply a very robust design that may present serious construction challenges.

\subsection{Implementation of the Design Procedure: More Efficient Narrow Stern Design}

In order to optimize structural efficiency, we suggest reshaping the side-hulls by widening the critical cross section and tapering toward the stern to reduce the bending moments. We decided to widen the connection point of the side-hull from 50 to $60 \mathrm{~m}$ and examine a reduction in the stern's radius $\left(R_{3}\right)$ from 25 to 20,15 , and $10 \mathrm{~m}$. With the constant deck and basin area constraint maintained, the frontal (delta shaped) deck length and connection fillet were slightly adjusted as well. Figures 11-13 present the VLFS top view for $R_{3}=10,15$, and $20 \mathrm{~m}$.

The new designs were first evaluated in terms of hydrodynamic performance (RAOs and efficiency of the protected basin), as detailed by [10]. The narrowest stern design of $R_{3}=10 \mathrm{~m}$ presents the best performance in these terms. As it is also ideal in reducing the bending moment, we decided to adopt this design. 

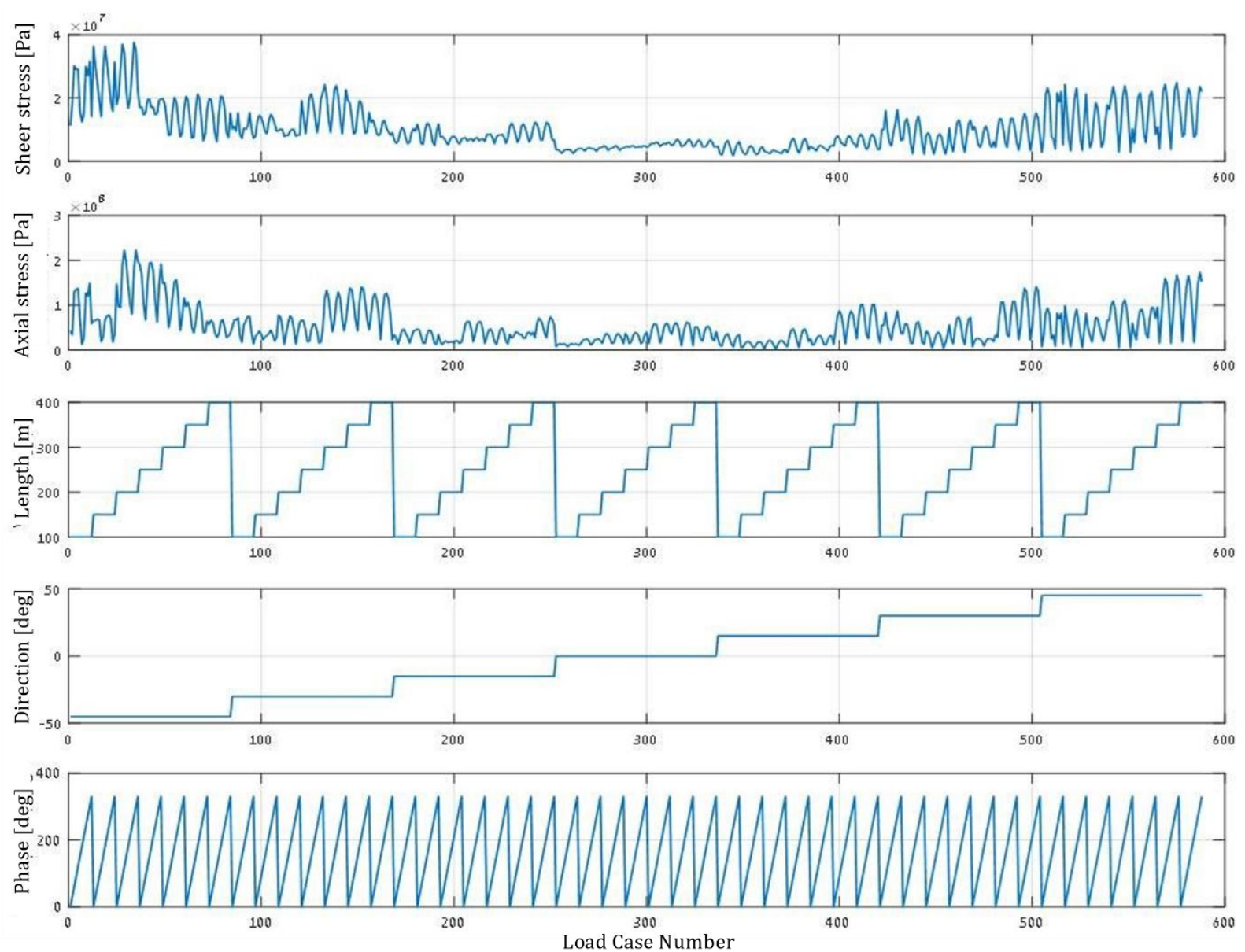

Figure 10. Illustration of the interactive plot (procedure output)- Shear and axial stresses using the simplified analytical model for hull girder primary strength. From top to bottom: shear stress (results), axial stress (results), wavelength (input), wave direction (input), and wave phase (input). The $x$ axis presents the serial number of the load case (wave combinations). As can be observed, the potentially critical load cases are readily identified as the two peak axial stress value of the $200 \mathrm{~m}^{\prime}-45^{\circ}$ wave (on the left side of the axial stress plot). Note that the interactive property of this plot could not be presented here.

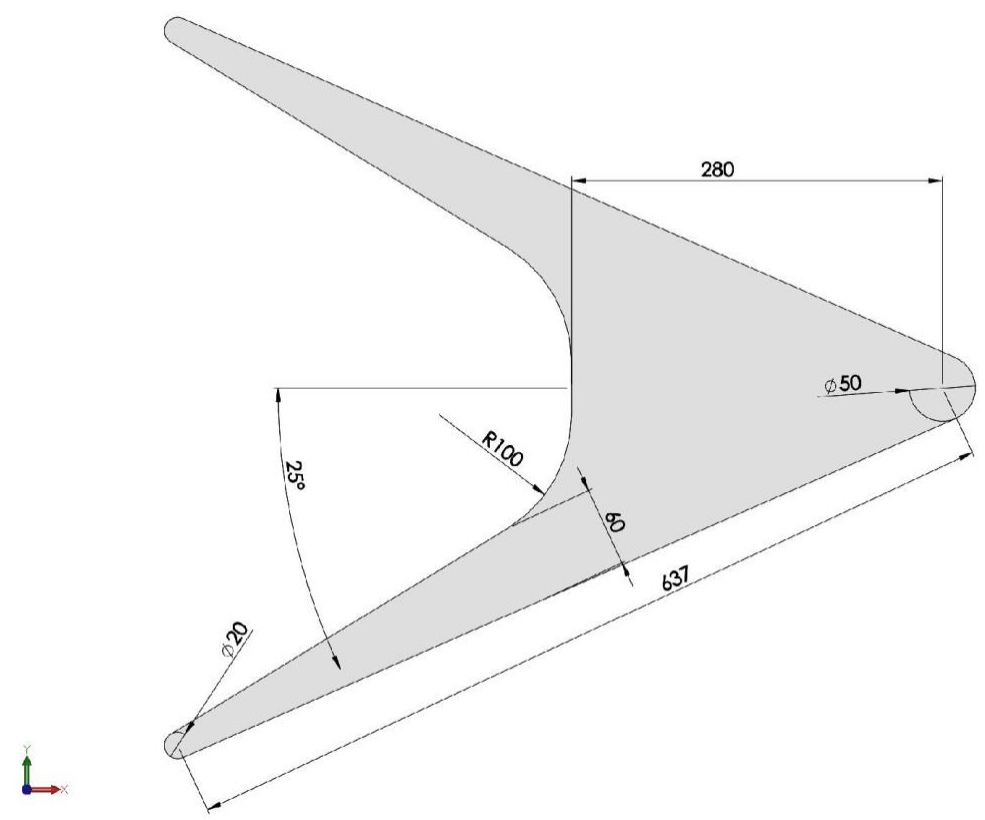

Figure 11. Delta VLFS with stern radius $\boldsymbol{R}_{\mathbf{3}}=\mathbf{1 0} \mathbf{~ m}$ (20 $\mathrm{m}$ stern diameter). 


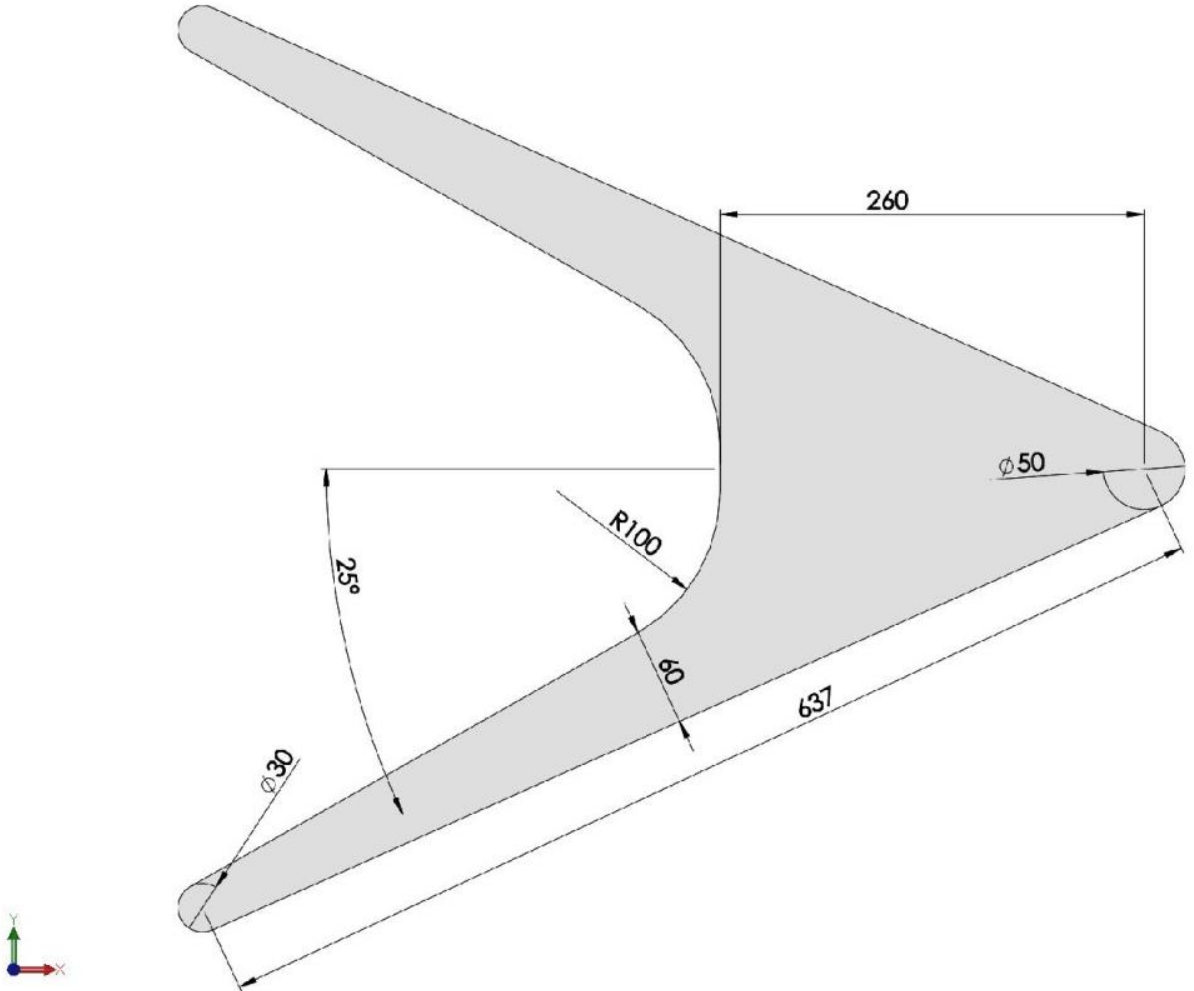

Figure 12. Delta VLFS with stern radius $\boldsymbol{R}_{\mathbf{3}}=\mathbf{1 5} \mathbf{~ m}$ (30 $\mathrm{m}$ stern diameter).

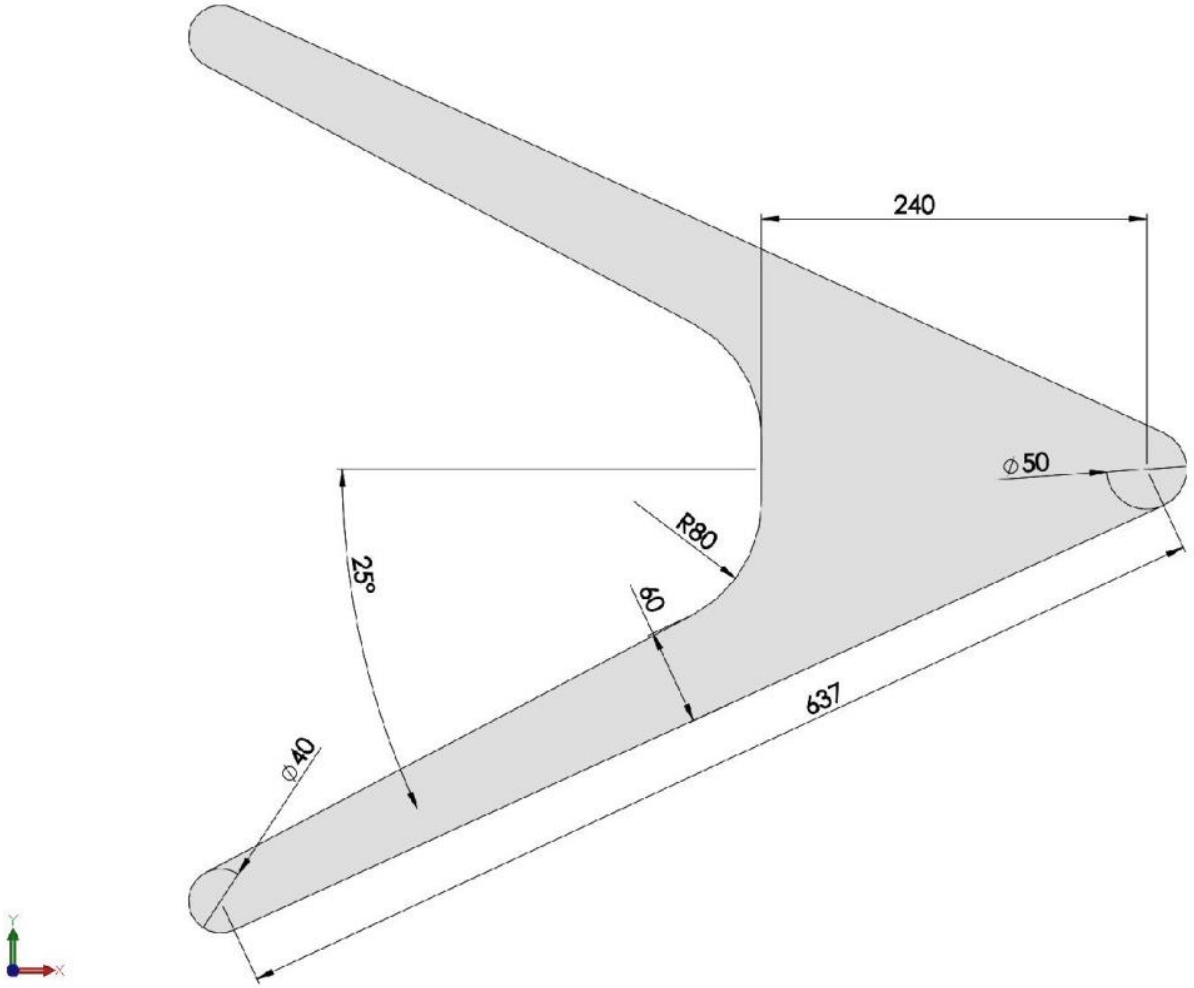

Figure 13. Delta VLFS with stern radius $\boldsymbol{R}_{\mathbf{3}}=\mathbf{2 0} \mathbf{m}$ (40 $\mathrm{m}$ stern diameter).

\subsubsection{Load Results}

By adopting the narrowest stern design of $R_{3}=10 \mathrm{~m}$, we present here the primary strength assessment using the simplified analytical hydrostatic model and the complete hydrodynamic splitting forces analysis. 
For this analysis, we examine combinations of the following wave parameters:

- Wave height: $10 \mathrm{~m}$;

- Wavelength: 200, 250, 300, 350, 400, 450 m;

- Wave phase: $0^{\circ}$ to $330^{\circ}$, in $30^{\circ}$ intervals. Phase $0^{\circ}$ is where the wave crest is at LCG;

- Wave direction: $45^{\circ}, 30^{\circ}, 15^{\circ}, 0^{\circ},-15^{\circ},-30^{\circ},-45^{\circ}$.

Figure 14 presents the maximal axial bending stress (for both vertical and horizontal bending moments simultaneously) for each wave scenario. The magenta lines present the simplified hydrostatic results, while the blue lines present the complete hydrodynamic analysis. For comparison with the initial design, we kept the original bending moduli.

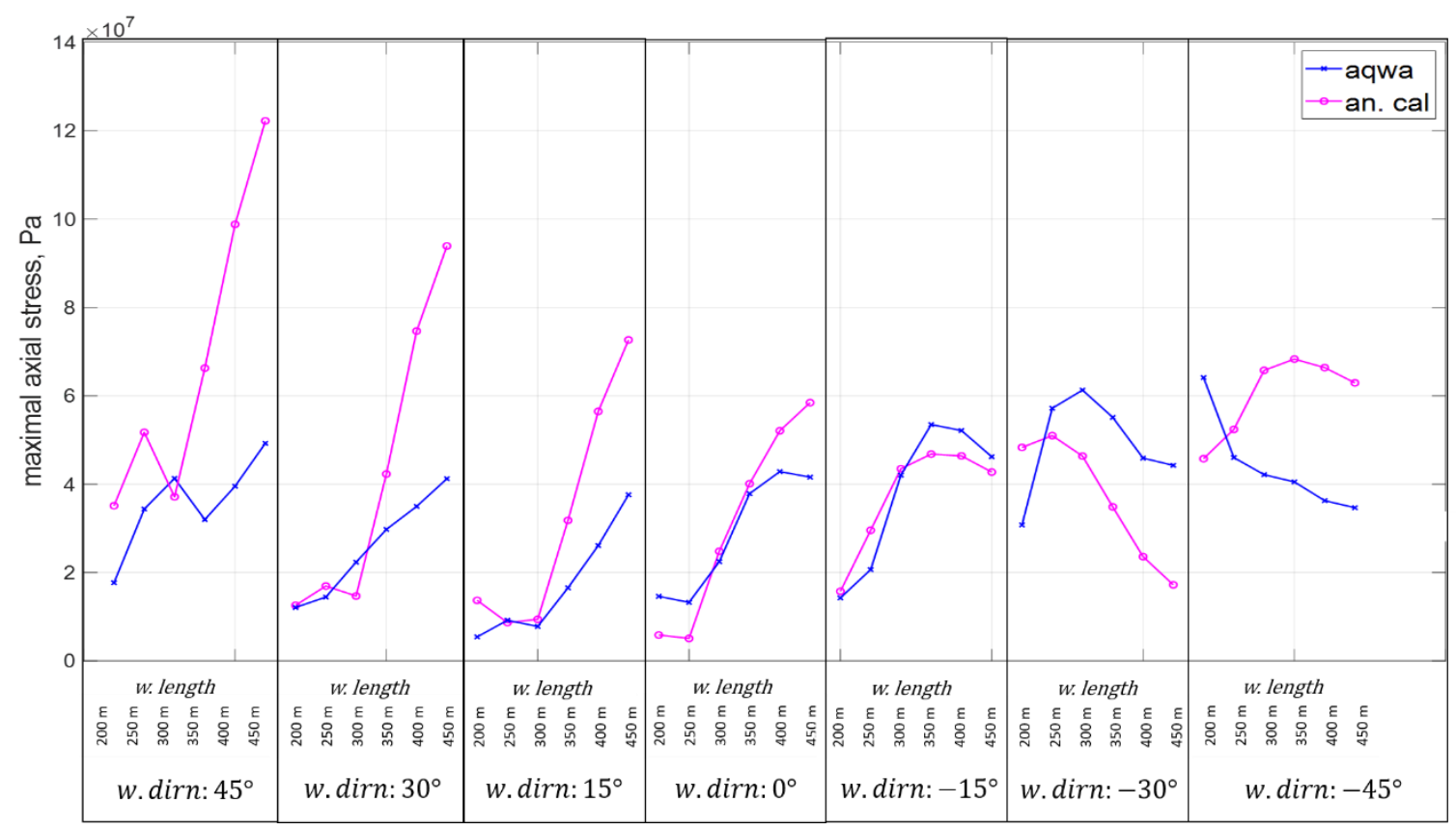

Figure 14. A comparison of the maximal axial stress in the $X$ direction at the critical cross section. The wave splitting forces calculation by AQWA (complete hydrodynamic moments) is in blue. The hydrostatic analytic calculation is in magenta. Each subplot presents a wave direction. For each direction, the wavelength increased from 200 to $450 \mathrm{~m}$.

\subsubsection{Initial Scantlings}

As discussed, the determination of the actual scantlings requires rigorous hydrodynamic-structural analysis. However, we present an initial design based on the results of the simplified analytical hydrostatic analysis. In order to enable global finite element analysis of the hull girder within reasonable computation time in the next stage of the research, this preliminary design consists of simple structural members (webs only). The initial scantlings are limited to the hull and decks' plating thicknesses and the dimensions and spacing of the longitudinal stiffeners and transverse frames. Figure 15 presents the critical cross section. 


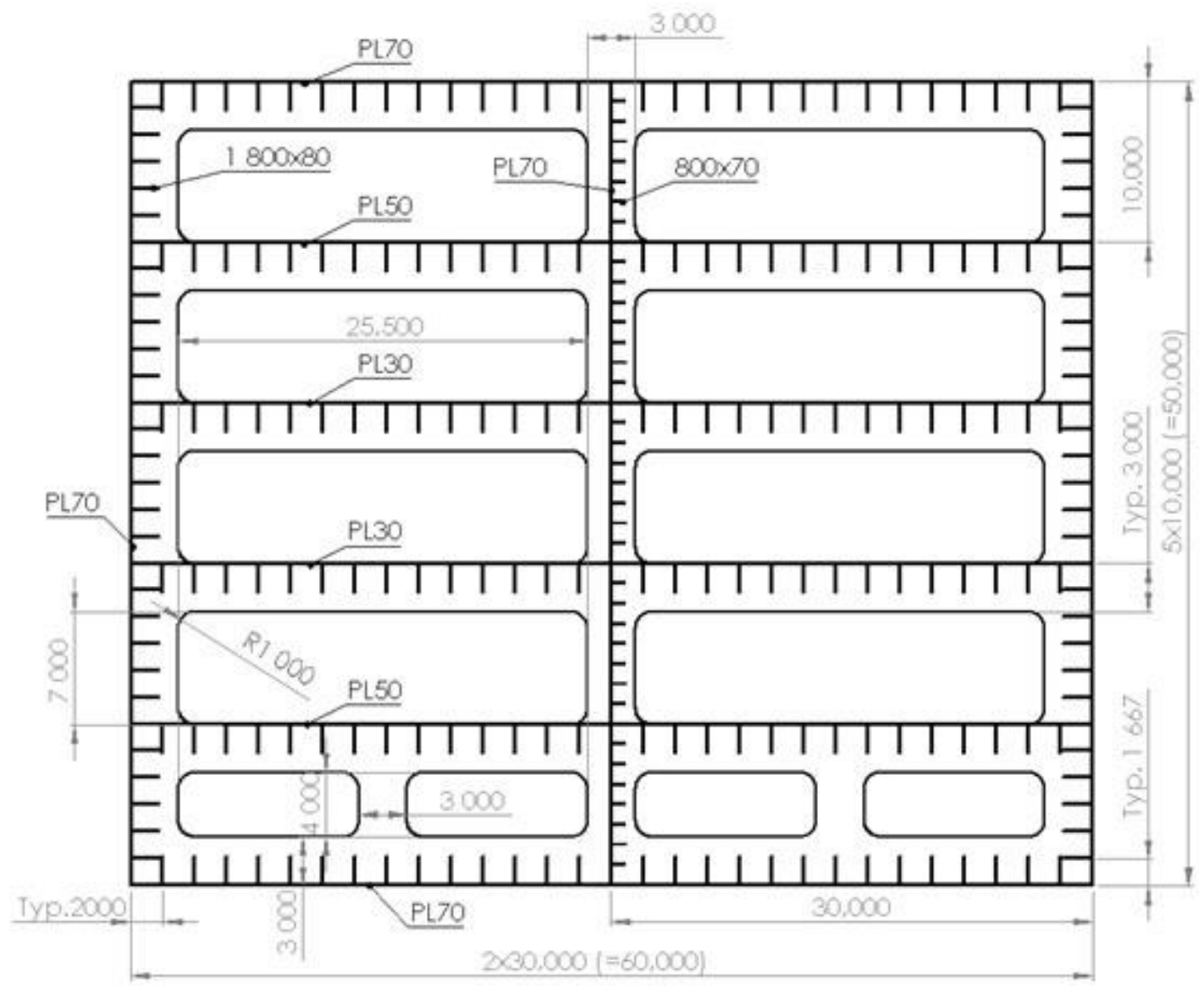

Figure 15. Initial scantling presented at the critical cross section. The plate thicknesses and stiffeners' dimensions and spacing are typical for the entire structure. All dimensions are in millimeters.

The hull has five floors of equal height and four internal decks. As presented in Figure 16, the preliminary design presents transverse bulkheads, dividing the hull into compartments of about $30 \mathrm{~m}$ in length. The typical spacing of transverse frames is $6000 \mathrm{~mm}$. A longitudinal midwall provides additional stiffness to the structure and decreases the span of each transverse frame.

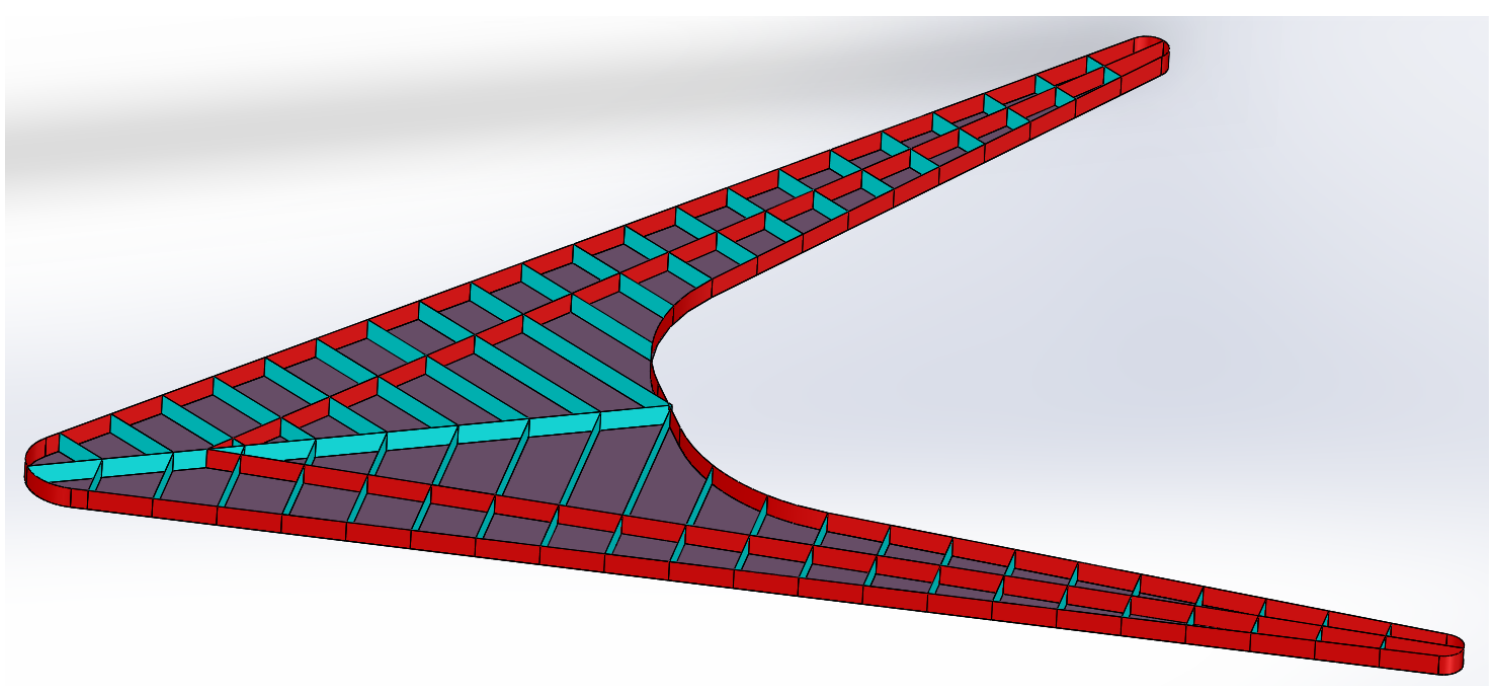

Figure 16. Compartment division on a single floor. Each compartment is about $30 \mathrm{~m}$ in length. 


\section{Discussion}

This study developed a practical (analytical) procedure to assess the primary strength of a unique hull. The method assumes hydrostatic floatation on a wave surface, as is practical in ship design. The analytical formulation enables fast scanning of hundreds of combinations of wave parameters to find the ones that are most critical, which, unlike traditional marine structures, are not trivial to assess.

The verification and validation that we presented, applying GHS, AQWA, and SOLIDWORKS, showed that the method is valuable as an initial stage before setting a complex hydrodynamic-structural model.

A comparison of the results of the analytical hydrostatic procedure with those of the complete hydrodynamic analysis show that, generally, the critical moments are higher when using the former hydrostatic procedure. Hence, they are useful for the initial estimation of the primary loads and for designing the preliminary scantlings required to set up a structural FE model.

In terms of the critical load cases, an inspection of the analytical and the hydrodynamic results brings about the same conclusions. Of the tested cases, a $450 \mathrm{~m}$ wave in a $45^{\circ}$ direction and a $200 \mathrm{~m}$ wave in a $-45^{\circ}$ direction are the most severe load cases.

The initial assessment of primary strength led us to optimize the geometry of the side-hulls from the prismatic to the tapered hull, which significantly reduced primary stress, optimized structural efficiency, and improved hydrodynamic performance. Table 1 presents a comparison of the primary loads applied by the critical wave at the critical cross section between the new tapered configuration and the initial prismatic design.

Table 1. A comparison of the critical wave bending moments. In the table, "prismatic" refers to the initial design (see Figure 9) and "tapered" refers to the improved design (see Figure 11).

\begin{tabular}{ccc}
\hline & Vertical Bending Moment $(\mathbf{M y})$ & Horizontal Bending Moment $(\mathbf{M z})$ \\
\hline Prismatic (initial) & $1.85 \times 10^{11} \mathrm{Nm}$ & $4.7 \times 10^{10} \mathrm{Nm}$ \\
\hline Tapered $\left(R_{3}=10\right)$ & $1.17 \times 10^{11} \mathrm{Nm}$ & $6.4 \times 10^{9} \mathrm{Nm}$ \\
\hline Reduction (\%) & $37 \%$ & $\mathbf{8 6} \%$ \\
\hline
\end{tabular}

By applying the preliminary design tool, we specified the initial scantlings (see Figure 15) in order to meet strength requirements. This initial design is required to set up the global FE model of the structure, with no previous operational experience of similar hulls and no design rules.

Simplifying the initial scantlings by using bar stiffeners will enable a global FE model for this huge hull. We expect that the actual design will implement more efficient structural members (e.g., L, T, or bulb profiles) of equivalent strength, which will reduce weight and provide more stability to prevent local buckling.

\section{Conclusions}

This paper contributes to the engineering practice on the structural design of large and unique marine structures in two ways: (1) provides a novel and efficient procedure for primary strength analysis and (2) presents the concept development and the structural design of a new concept of VLFS- the Delta Type.

When compared to more detailed and exact analyses, such as FE or BEM (splitting forces), the presented analytic procedure is a valuable and efficient tool for preliminary design. It provides satisfactory initial assessment of the primary strength requirements of the structure within a minimal time frame and requires moderate modeling efforts and computer resources. Its implementation for the design of the Delta, as presented in this paper, required less than an hour from pre-processing and running the 588 load cases to obtaining the results.

The improvement of the scantling by widening the connections and tapering the sidehulls significantly reduced the applied bending moments and improved the hydrodynamic 
attributes of the structure. The reduced strength requirements allow for more efficient and practical structural design. A following study will present a comprehensive combined hydrodynamic-structural analysis relative to critical loading cases.

Author Contributions: Conceptualization, N.D. and R.G.; methodology, R.G.; software, R.G.; validation, N.D. and R.G.; formal analysis, R.G.; investigation, R.G.; resources, N.D.; data curation, N.D.; writing-original draft preparation, R.G.; writing—review and editing, N.D.; visualization, R.G.; supervision, N.D.; project administration, N.D.; funding acquisition, N.D. All authors have read and agreed to the published version of the manuscript.

Funding: This research was funded by The Israel Ports Development \& Assets Company Ltd., grant number 2024706. The APC was funded by Technion- Israel Institute of Technology.

Institutional Review Board Statement: Not applicable.

Informed Consent Statement: Not applicable.

Conflicts of Interest: The authors declare no conflict of interest.

\section{References}

1. Wang, G.; Goldfeld, Y.; Drimer, N. Expanding coastal cities-Proof of feasibility for modular floating structures (MFS). J. Clean. Prod. 2019, 222, 520-538. [CrossRef]

2. UNCTAD. Handbook of Statistics 2020-The World Development Status; United Nations Publications: New York, NY, USA, 2020; ISBN 9789211129977.

3. Ranasinghe, R. On the need for a new generation of coastal change models for the 21st century. Sci. Rep. 2020, 10, 2020. [CrossRef]

4. Wang, C.M.; Wang, B.T. Colonization of the ocean and VLFS technology. In Very Large Floating Structures; Wang, C.M., Watanabe, E., Utsunomiya, T., Eds.; Taylor \& Francis: London, UK; New York, NY, USA, 2008; pp. 1-20. ISBN 9788578110796.

5. Wang, C.M.; Tay, Z.Y. Very Large Floating Structures: Applications, Research and Development. Procedia Eng. $2011,14,62-72$. [CrossRef]

6. Wang, C.M.; Wang, B.T. Great Ideas Float to the Top. In Large Floating Structure: Technological Advances; Wang, C.M., Wang, B.T., Eds.; Springer Science Business Media: Singapore, 2015; p. 334. ISBN 978-981-287-137-4.

7. Kim, J.-G.; Cho, S.-P.; Kim, K.-T.; Lee, P.-S. Hydroelastic design contour for the preliminary design of very large floating structures. Ocean Eng. 2013, 78, 112-123. [CrossRef]

8. Wu, L.; Wang, Y.; Li, Y.; Xiao, Z.; Li, Q. Simplified algorithm for evaluating the hydrodynamic performance of very large modular semi-submersible structures. Ocean Eng. 2017, 140, 105-124. [CrossRef]

9. Lamas-Pardo, M.; Iglesias, G.; Carral, L. A review of Very Large Floating Structures (VLFS) for coastal and offshore uses. Ocean Eng. 2015, 109, 677-690. [CrossRef]

10. Drimer, N.; Gafter, R. Delta-type VLFS—hydrodynamic aspects. Ships Offshore Struct. 2017, 13, 352-365. [CrossRef]

11. Hughes, F.O.; Paik, J.K. Ship Structural Analysis and Design; The Society of Naval Architects and Marine Engineers: Jersey City, NY, USA, 2010

12. Sidari, M.; Andric, J.; Jelovica, J.; Underwood, J.M.; Ringsberg, J.W. Influence of different wave load schematisation on global ship structural response. Ships Offshore Struct. 2019, 14, 9-17. [CrossRef]

13. Payer, H.G.; Schellin, T.E. A class society's view on rationally based ship structural design. Ships Offshore Struct. 2013, 8, 319-336. [CrossRef]

14. McNatt, T.; Ma, M.; Hunter, S. Historical perspective on the structural design of special ships and the evolution of structural design methods. Ships Offshore Struct. 2013, 8, 404-414. [CrossRef]

15. Suzuki, H.; Bhattacharya, B.; Fujikubo, M.; Hudson, D.A.; Riggs, H.R.; Seto, H.; Shin, H.; Shugar, T.A.; Yasuzawa, Y.; Zong, Z. ISSC 2006-Committee VI.2: Very Large Floating Structures. In Proceedings of the 16th International Ship and Offshore Structures Congress, Southampton, UK, 20 August 2006; Volume 2, pp. 1-236.

16. Pei, Z.; Iijima, K.; Fujikubo, M.; Tanaka, S.; Okazawa, S.; Yao, T. Simulation on progressive collapse behaviour of whole ship model under extreme waves using idealized structural unit method. Mar. Struct. 2015, 40, 104-133. [CrossRef]

17. Odijie, A.C.; Quayle, S.; Ye, J. Wave induced stress profile on a paired column semisubmersible hull formation for column reinforcement. Eng. Struct. 2017, 143, 77-90. [CrossRef]

18. Cariou, A.; Jancart, F. Influence of modelling on calculated sea loads on ships. Mar. Struct. 2003, 16, 149-173. [CrossRef]

19. Phelps, B.P. DSTO-RR-0116: Determination of Wave Loads for Ship Structural Analysis; Aeronautical and Maritime Research Laboratory: Melborne, Australia, 1997.

20. Tatsumi, A.; Fujikubo, M. Ultimate strength of container ships subjected to combined hogging moment and bottom local loads part 1: Nonlinear finite element analysis. Mar. Struct. 2019, 69, 102683. [CrossRef]

21. Liu, B.; Soares, C.G. Ultimate strength assessment of ship hull structures subjected to cyclic bending moments. Ocean Eng. 2020, 215, 107685. [CrossRef]

22. Yao, T. Hull Girder Strength. Mar. Struct. 2003, 16, 1-13. [CrossRef] 
23. Lee, D.H.; Kim, S.J.; Lee, M.S.; Paik, J.K. Ultimate limit state based design versus allowable working stress based design for box girder crane structures. Thin-Walled Struct. 2019, 134, 491-507. [CrossRef]

24. Paik, J.K.; Wang, G.; Kim, B.J.; Thayamballi, A.K. Ultimate Limit State Design of Ship Hulls. 2002, Volume 110, pp. 473-496. Available online: https:/ / www.zhangqiaokeyan.com/academic-journal-foreign_other_thesis/020419986339.html (accessed on 15 September 2021).

25. Kuznecovs, A.; Ringsberg, J.W.; Johnson, E.; Yamada, Y. Ultimate limit state analysis of a double-hull tanker subjected to biaxial bending in intact and collision-damaged conditions. Ocean Eng. 2020, 209, 107519. [CrossRef]

26. Yoshkawa, T.; Bayatfar, A.; Kim, B.J.; Chen, C.P.; Wang, D.; Boulares, J.; Gordo, J.M.; Josefson, L.; Smith, M.; Kaeding, P.; et al. Issc2015-Committee III 1: Ultimate Strength. In Proceedings of the 19th International Ship and Offshore Structures Congress, Cascais, Portugal, 7-10 September 2015.

27. Paik, J.K.; Kim, B.J.; Seo, J.K. Methods for ultimate limit state assessment of ships and ship-shaped offshore structures: Part I-Unstiffened plates. Ocean Eng. 2008, 35, 261-270. [CrossRef]

28. International Association of Classification Societies. Common Structural Rules for Bulk Carriers and Oil Tankers; IACS: London, UK, 2020.

29. Jagite, G.; Bigot, F.; Derbanne, Q.; Malenica, Š.; Le Sourne, H.; Cartraud, P. A parametric study on the dynamic ultimate strength of a stiffened panel subjected to wave- and whipping-induced stresses. Ships Offshore Struct. 2020, 1-15. [CrossRef]

30. Kaminski, M.L.; Rigo, P. Progress in Marine Science and Technology. In Proceedings of the 20th International Ship and Offshore Structures Congress (ISSC 2018); Kaminski, M.L., Rigo, P., Eds.; IOS Pres BV: Amsterdam, The Netherlands, 2018; Volume 1, ISBN 978-1-61499-862-4.

31. ANSYS Inc. AQWA Theory Manual; ANSYS Inc.: Canonsburg, PA, USA, 2013; Volume 15317.

32. Journee, J.M.J.; Massie, W.W. Offshore Hydromechanics, 1st ed.; Delft University of Technology: Delft, The Netherlands, 2001; ISBN 9781457717659. 